\title{
El islam en el espacio público de los barrios multiculturales del sur de Europa: el caso de Lavapiés, Madrid
}





\title{
El islam en el espacio público de los barrios multiculturales del sur de Europa: el caso de Lavapiés, Madrid ${ }^{1}$
}

\section{Islam in the public space of multicultural neighbourhoods in southern Europe: the case of Lavapiés, Madrid}

\author{
Oscar Salguero Montaño \\ Universidad Complutense de Madrid (España) \\ oscarsal@ucm.es
}

Fecha de recepción: 23 de diciembre de 2019

Fecha de aceptación: 28 de septiembre de 2020

\begin{abstract}
Resumen
En las actuales sociedades plurales no confesionales, los grupos religiosos entienden el acceso al espacio público como un derecho a la ciudad. Este derecho legitima su condición de actores sociales, que traducen como visibilización en el espacio público y participación en la vida política del municipio, a través de diversas nociones vinculadas a la modernidad y la transparencia. Para explorar esta hipótesis, este artículo examina el caso de los musulmanes bangladeshíes del multicultural barrio madrileño de Lavapiés, el cual presenta semejanzas con otros barrios multiculturales de ciudades del sur de Europa como Lisboa o Roma: un barrio afectado por un acelerado proceso de gentrificación y turistificación. Se analizan las circunstancias en las que esta comunidad intenta acceder al espacio público, con el fin de lograr una mayor legitimación y reconocimiento, teniendo en cuenta las diferentes prácticas y discursos que se despliegan en determinados eventos y festividades.
\end{abstract}

Palabras claves: Islam; Islam bangladesí; Espacio público; Derecho a la ciudad; Madrid.

1 Este texto ha sido elaborado en el marco del proyecto CSO2015-66198-P "Expresiones religiosas en el espacio urbano de Madrid y Barcelona (EREU-MyB)", Dirección General de Investigación Científica y Técnica y Subdirección General de Proyectos de Investigación del Ministerio de Economía y Competitividad, Excelencia en I+D+i, convocatoria 2015. 


\begin{abstract}
In current nondenominational plural societies, religious groups understand access to public space as a right to the city. This right legitimizes their status as social actors, who are entitled to have a public life and to be recognized, through various notions linked to modernity and transparency. To explore this hypothesis, this article examines the case of Bangladeshi Muslims in Madrid's multicultural neighborhood of Lavapiés, which has similarities with other multicultural neighborhoods in southern European cities, which has similarities with other multicultural neighbourhoods in southern European cities, such as Lisbon or Rome: a barrio affected by an accelerated gentrification and touristification process. It analyzes the circumstances through which this community attempts to access public space, in order to achieve further legitimization and recognition, by bringing into account the different practices and discourses displayed in specific events and festivities.
\end{abstract}

Keywords: Islam; Bangladeshi Islam; Public space; Right to the city; Madrid (Spain)

\title{
1. REGONOGIMIENTO DE LA DIFERENGIA Y DEREGHO A LA INCLUSIÓN
}

El islam en las sociedades occidentales es una de las confesiones más diversificadas en términos de etnia y de país de origen por los flujos transnacionales de creyentes procedentes de países con diversas tradiciones y escuelas jurisprudenciales islámicas, además de otras prácticas y costumbres no religiosas que inciden igualmente en la forma de entender el hecho religioso y cómo organizarse en torno al mismo (Shepard, 2004), especialmente en colectivos como jóvenes (Hamid, 2011, pp. 252-257; Téllez y Madonia, 2019, p. 124) y mujeres (Repo, 2013, p. 177; Ramírez y Mijares, 2018, pp. 145-146). Además, el islam coexiste con otras confesiones en un "mercado religioso" plural (Berger, 1967; Luckmann, 1967) que, en gran medida, es resultado de los efectos de los flujos migratorios y sus redes transnacionales (Casanova, 2007; Castilla-Vázquez, 2011) y con importantes variaciones en las tradiciones devocionales. En el caso de España, el mapa religioso se caracteriza por "la pluralidad de sacralidades, la fragmentación" (Moreno, 1998, p. 170) y por la "persistencia" de lo religioso como relación a lo sagrado bajo formas nuevas que han entrañado un proceso de "recomposición-descomposición" (Briones, 2002, p. 295). Según datos del Observatorio del Pluralismo Religioso en España, en octubre de 2019, el islam es la tercera confesión en número de lugares de culto, con 1.695; por detrás de las 4.362 iglesias evangélicas y las 23.021 parroquias católicas.

Las confesiones están sujetas a un marco legal determinado por la aconfesionalidad del Estado y las garantías del derecho de libertad religiosa y culto, lo que plantea a las instituciones públicas nuevos retos y desafíos, presionándolas para una implicación más explícita que se materializa, en el caso del islam, en 
una "nueva forma de gestión que favorece una aproximación más democrática e inclusiva hacia este fenómeno, pero a su vez conlleva también una intensificación de la monitorización, la regulación y el control de las organizaciones religiosas" (Astor y Griera, 2016, p. 247).

Nociones como espacio público, ciudadanía y secularización, han sido revisadas ante la progresiva transformación multicultural de las sociedades europeas, un debate que ha tomado a la "nueva presencia" musulmana en el viejo continente como "ejemplo y también como límite para extender el principio de reconocimiento" (Moreras, 2017: 16). La ciudadanía, que apunta a la definición de la identidad de los individuos en el espacio público (Thiebaut, 1998, p. 24), incluida la de los creyentes, engloba una serie de derechos que van de la pertenencia plena a una comunidad política como miembros de la misma y respetados en su singularidad (reconocimiento de la diferencia), hasta su participación activa en la misma (derecho a la inclusión); y, a su vez, responde a una serie de "exigencias" sociales relacionadas con la modernidad de las confesiones, y, en casos como el islam, también con la transparencia. El énfasis en la diversidad se caracteriza por la reivindicación de lo distintivo y la búsqueda de una voz propia en la sociedad, más en la línea de la "ciudadanía religiosa" expuesta por Hudson (2003), en virtud de la cual los marcos normativos y la propia institución de la ciudadanía necesitarán ser reconstituidos de acuerdo con principios pluriconfesionales, además de seculares.

Esta reivindicación tanto de la diversidad, como del derecho a la inclusión de los grupos religiosos, convierten al espacio público en espacio político para el ejercicio de los derechos cívicos y en espacio para la alteridad (Alguacil, 2008, p. 204), pues lo definitorio del mismo es su tendencia "a la mezcla social", entendido como "un derecho ciudadano de primer orden", de modo que garantice "en términos de igualdad la apropiación por parte de diferentes colectivos sociales y culturales, de género y de edad" (Borja y Muxí, 2003, p. 11). La creciente visibilidad en el espacio público de la diversidad religiosa ha venido acentuada por el hecho de que "aquellos que optan seriamente por la religión en las sociedades europeas quieren hacer oír su voz tanto en público como en privado" (Davie, 2004, p. 80). El derecho a la inclusión en el espacio público forma parte, por tanto, del "derecho a la ciudad" (Lefebvre, 1968), es un derecho fundamental en la ciudad porque es desde donde "se construyen la expresión e identificación social de los diversos" (Carrión, 2007, p. 84).

A partir de ello, esta investigación estudia el caso de la comunidad musulmana bangladesí del barrio madrileño de Lavapiés, prestando especial interés en las circunstancias en las que intenta acceder al espacio público, con el fin de lograr una mayor legitimación social y reconocimiento institucional, teniendo en cuenta las diferentes prácticas y discursos que se despliegan en determinados eventos seculares y festividades religiosas. 


\section{CUESTIONES METODOLÓGICAS}

Este estudio parte del acervo de haber estado inserto en una investigación de mayores dimensiones, desarrollada en las ciudades de Barcelona y Madrid e integrada por diversos casos correspondientes a distintas confesiones de una y otra urbe entre un total de 41 investigadores/as ${ }^{2}$.

El colectivo bangladesí de Lavapiés ha requerido un intenso y continuado trabajo etnográfico, que ha incluido la realización de una serie de entrevistas con informantes clave, seleccionados entre distintos actores: religiosos, de la propia comunidad, de otras comunidades vecinas musulmanas y también de otras confesiones; públicos, que han incluido a la concejalía del distrito y una técnica municipal; y asociativos, con el personal de una organización que trabaja con la comunidad bangladesí. También han surgido entrevistas informales que han aportado valiosa información con personal público participante en algunas de las actividades (policías, sanitarios y protección civil), vecinos y vecinas y comerciantes del barrio.

Además, la presencia continuada en el espacio público a lo largo del año con diferentes actividades, ha traído consigo que las técnicas de observación hayan desempeñado igualmente un relevante papel, basculando entre la observación directa (caso de la oración de fin del Ramadán, donde el ritual fue recogido casi sin interacción con los fieles); y la participante (caso del iftar en el que el papel del investigador no diferiría notablemente del resto de asistentes), llegando en alguna ocasión por reciprocidad a desempeñarse otros roles distintos al de observador (caso de unas jornadas de puertas abiertas en las que a petición de los organizadores, se presentó públicamente la investigación tras las intervenciones de los representantes municipales, dotando así al acto de mayor institucionalidad, pues a la presencia del Ayuntamiento y de la Comisión Islámica de España, se sumaba ahora la de la Universidad).

El contexto multicultural y plurireligioso de Lavapiés ha hecho pertinente acercarse no sólo a otras mezquitas, como Al-Huda, sino también a otras confesiones vecinas de Lavapiés, como la parroquia católica de San Millán, cuyo párroco está comprometido con el diálogo interreligioso y la integración social en el barrio. Para este otro apartado del trabajo de campo, de ejecución simultánea, se emplearon también las técnicas citadas; si bien, aspectos como la cercanía de la vecindad propiciaron, por ejemplo, que las observaciones a veces tan solo consistieran en un pausado paseo por las calles de un campo conocido, el del propio barrio del investigador, algo así como una deriva del flâneur, y a través del cual han podido registrarse situaciones y espacios no previstos en un primer momento. En este sentido, la investigación ha sido eminentemente adaptativa a las sucesivas circunstancias que han ido surgiendo durante el trabajo de campo.

\footnotetext{
2 https://urbanreligions.uab.cat/en/
} 
En la base de la investigación también se han empleado una serie de fuentes de carácter documental, técnico y jurídico: fuentes estadísticas oficiales y algunas otras de organismos relacionados, como el Registro de Entidades Religiosas del Ministerio de Justicia o el Observatorio del Pluralismo Religioso en España, así como de las propias confesiones, como los informes anuales del Observatorio Andalusí, adscrito a la Unión de Comunidades Islámica de España (UCIDE); prensa online, que ha permitido contrastar algunos de los hechos pasados narrados durante las entrevistas y acercarse a los discursos institucionales de actores relevantes como el Ayuntamiento; legislación y normativa administrativa afecta, en sus niveles estatal, autonómico y local; y una serie de programas y planes de organismos públicos relacionados.

\section{MULTICULTURALIDAD, PLURALISMO RELIGIOSO Y GENTRI- FICACIÓN}

Lavapiés es el nombre con el que se conoce popularmente a una gran parte del barrio de Embajadores, en el distrito Centro de Madrid. Fue descrito por Ramón de Mesoneros en 1861 como un barrio "castizo" (2005, p. 189) por su identidad cultural poco o nada cosmopolita que arraigaría especialmente en las clases obreras y el folclore del Madrid de los siglos XVIII y XIX. Sin embargo, desde mediados de los noventa, comenzó a asentarse un importante volumen de población migrante no comunitaria (Gómez, 2012, p. 5), erigiéndose en los últimos años como uno de los principales enclaves multiculturales de la capital (Peñalta, 2010, p. 111). Según datos municipales, a 1 de enero de 2019, la población censada en el distrito Centro era de 135.314 personas, siendo el barrio de Embajadores el que mayor población alberga con 45.433, 11.908 de las cuales ostentan alguna de las 88 nacionalidades distintas a la española, lo que lo convierte en el barrio de Madrid con mayor población extranjera. Las nacionalidades más numerosas después de la española, son la italiana con 3.194 personas y la bangladesí con otras 2.935 , la cual, desde los últimos años, crece continuamente, pasando de 4.622 personas en 2016 a 6.288 en 2019.

En este contexto multicultural, Lavapiés es también un barrio plurireligioso. En su espacio público tienen lugar manifestaciones religiosas tan variopintas como el traslado del sinpecado de la Hermandad del Rocío de Madrid, una celebración católica "popular", o los rezos islámicos del fin del Ramadán y de la fiesta del sacrificio, pasando por prácticas proselitistas como las del grupo evangélico On The Red Box. Además, el barrio alberga numerosos lugares de culto de distintas confesiones: en septiembre de 2019, junto a la confesión católica, que cuenta en el barrio con las históricas parroquias de San Millán y San Cayetano en la zona alta y de San Lorenzo en la baja, existen siete comunidades evangélicas de diversas denominaciones (bautistas, pentecostales, Filadelfia...); seis lugares de culto islámico (de distintas procedencias: marroquí, bangladesí, pakistaní y senegalesa); dos centros budistas (uno zen y otro tibetano); un salón del reino de los testigos de Jehová; y cuatro lugares de culto de otras confesiones (rosacruces, paganos, etc.). 
Muchos de estos lugares de culto se encuentran en pequeños locales bajos, camuflados entre tiendas y locales de ocio. En el caso de las comunidades musulmanas, ninguna de las dos mezquitas más grandes del barrio, Baitul Muqarram y el Centro Religioso de Pakistaníes de España, cuentan con espacio suficiente para acoger en su interior a todos los fieles que acuden a la oración del viernes y a las grandes celebraciones, y es que contar con un lugar de culto acorde con las necesidades comunitarias sigue presentando una serie de dificultades relacionadas con una "precariedad endémica de recursos" (Alonso et al., 2010, p. 171). Junto a esta necesidad, las comunidades más consolidadas, ahora también pretenden visibilizarse en el espacio público a través de distintas estrategias como la celebración de festividades religiosas multitudinarias como el rezo colectivo del Eid al-Fitr que anualmente organiza Baitul Muqarram; pero también a través de prácticas proselitistas como la ubicación de una carpa "informativa" en la céntrica plaza de Sol en 2016 durante la celebración de la Ashura por Alulbeyt, una fundación chiita duodecimana (Salguero and Hejazi, 2020, p. 3).

Una de las necesidades es el tema del espacio público (...) y la problemática de los lugares de culto. Siempre hay trabas administrativas para obtener una licencia de apertura, porque a veces aplican a los lugares de culto el régimen legal de otras actividades, como discotecas o industria, y esto no es así. Este tipo de trabas complican tanto al funcionario como a los vecinos musulmanas (miembro de la Comisión Islámica de España, 25/10/2016).

Al igual que muchos otros barrios multiculturales de los centros históricos, Lavapiés está sufriendo un profundo proceso de transformación social urbana auspiciado por el modelo de "ciudad capitalista", en el que el turismo desempeña un papel central, haciendo que la ciudad deje de planificarse como espacio para ser habitado y se oriente más a su mercantilización a través del desarrollo y la renovación urbana (Rodríguez-Medela, Salguero y Sánchez-Cota, 2016, p. 276). Para la atracción de visitantes y turistas, además de la implementación de una serie de prácticas especulativas sobre el suelo basadas en la gentrificación y turistificación (Sequera, 2014, p. 237), se ha promocionado la imagen de "barrio de moda" para el ocio y el turismo de fin de semana; asociada también a la de "barrio multicultural", ventaja competitiva que reflejan, incluso, algunos anuncios del portal inmobiliario Arbnb: "Beautiful and cozy terrace apartment in the heart of Lavapiés, typical and multicultural neighbourhood in Madrid". En marzo de 2017 la revista internacional de tendencias, Vice, dedicaba un exotista artículo a la vecindad musulmana de Lavapiés ${ }^{3}$; y en septiembre de 2018, el barrio era declarado por la revista internacional de ocio

3 Bernal, Fernando, "Así viven los musulmanes del barrio de Lavapiés de Madrid", Vice, 31 de marzo de 2017. Recuperado de: https://www.vice.com/es/article/kwj3gn/musulmanes-madridlavapies-3103 [acceso: 24/07/2020] 
Time Out como el barrio más cool de la City Life Index por "ser lugar de convivencia de gente de todas partes" y por su "vida cultural popular y frenética".

Como resultado de todo ello se ha producido un exponencial aumento del precio de la vivienda, especialmente la de alquiler (un $7,8 \%$ en 2018 y un $39,1 \%$ con respecto a 2014, según datos del portal inmobiliario idealista.com); la reconversión de gran parte del parque de vivienda residencial en turística; y la expulsión, a veces por desahucio, de los vecinos más precarios y con menos recursos, migrantes muchos de ellos.

Yo llevo 15 años en Lavapiés y voy a cambiar de barrio por la vergüenza de la situación económica. No me llega al mes para vivir con mi hijo y con mi mujer (miembro de Baitul Muqarram, 04/09/2019).

Estos vecinos expulsados son sustituidos por otros con más recursos económicos, como una elitista "clase creativa" que encuentra en Lavapiés una de las calles de Europa con más galerías de arte, Dr. Fourquet; o la creciente población flotante de turistas y visitantes de Airbnb, que quieren vivir las experiencias de los nativos y ocupan ya no solo los hoteles, plazas, monumentos y otros servicios, sino que también habitan y consumen los mismos espacios de los propios vecinos. Las preferencias de consumo de estos nuevos residentes y visitantes no encajan con el comercio tradicional (ultramarinos, arreglos de ropa y zapatos, tiendas de ropa "no moderna", bares "de toda la vida"...), el cual ha venido siendo igualmente sustituido por tiendas exclusivas y de importantes firmas, locales de ocio nocturno, establecimientos hosteleros de "comida étnica", gastrobares y restaurantes veganos.

Este modelo de desarrollo también ha traído consigo inconvenientes como el deterioro del mobiliario urbano, continuas molestias por ruido y salubridad o la venta de droga en la calle y en los "narcopisos", lo que recuerda a los años ochenta cuando era un barrio obrero castigado por la droga, cuando era "la periferia del centro". Hoy, pese a la gentrificadora reconversión del tejido social del barrio, en la enrevesada y populosa trama urbana de Lavapiés, con sus estrechas y empinadas calles, aún persisten la marginalidad (Gómez, 2012, p. 3) y correlativamente, desde la Guerra Civil, la infravivienda (Pérez, 2009), además de otros fenómenos como la "híperpresencia policial" y las "identificaciones preventivas" por criterios raciales (GarcíaGarcía, 2014, p. 8). Esta conflictividad ha generado que sea también un vecindario de muchos movimientos sociales y asociaciones (Rodríguez-Brochado, 2017, p. 126), centradas en la defensa de los derechos de los migrantes, del precariado, contra la gentrificación y la especulación inmobiliaria, el racismo, la LGTBIfobia, etc. (Salguero, 2018, p. 126; Méndez, 2019, p. 5).

4 Bac, Marta, "Un barrio de Madrid, elegido el mejor del mundo", Time Out, 21 de septiembre de 2018. Recuperado de: https://www.timeout.es/madrid/es/noticias/un-barrio-de-madrid-elegido-elmejor-del-mundo-092118 [acceso: 24/07/2020] 


\section{LA VEGINDAD "BANGLA"}

La literatura española sobre la diáspora bangladesí y el papel en la misma de las comunidades islámicas es muy reciente y escasa (Martín-Saiz, 2019; Méndez, 2019; Salguero, 2018, 2019; Salguero y Hejazi, 2020), no así con otros colectivos nacionales de mayor implantación y arraigo, como el marroquí. En cambio, en los estados europeos donde el colectivo bangladesí tiene una dilatada trayectoria, ha gozado de una mayor atención, como en Reino Unido (Eade, 1996; Eade y Garbin, 2002 y 2006; Dench, Gavron y Young, 2006), Italia (Priori, 2010 y 2017; Della Puppa, 2014; Morad and Della Puppa, 2018) y Portugal (Mapril, 2012, 2014, 2016 y 2018). En ciudades como Roma, Lisboa y Londres se observan dinámicas generales que también se observan en Madrid, como la concentración residencial de población bangladesí en barrios muy multiculturales, como Lavapiés, donde residen casi la mitad de los 6.288 connacionales censados, superando a otras nacionalidades de tradición islámica como la marroquí, que, pese a ser la mayoritaria en la capital, y en España, en el distrito Centro ha quedado significativamente mermada por una tendencia residencial centrífuga hacia el área metropolitana y municipios del sur como Alcorcón, Móstoles, Fuenlabrada, Getafe, Leganés o Parla (Eguren y Fernández, 2011, p. 236).

La vecindad bangla está conformada mayoritariamente por hombres jóvenes solos, residentes en domicilios compartidos con otros bangladesíes, o agrupados en familias jóvenes con hijos pequeños, manteniendo estrechas relaciones transnacionales con el país surasiático. En general, residen en viviendas precarias, en las que conviven desde cuatro a más personas en pocos metros cuadrados, pese a lo cual, la subida de precios les está afectando igualmente, pues estos abandonados inmuebles pueden generar mayores plusvalías reconvirtiéndose en apartamentos turísticos de fin de semana. Las cada vez más frecuentes expulsiones han motivado que la gentrificación sea también una de las preocupaciones de este vecindario y de sus redes asociativas.

Hay muchas familias banglas que se han ido de aquí, a Alcorcón, a Getafe... a San Cristóbal en Villaverde Alto, y a muchos sitios. Y también otras han cambiado de ciudad, porque en Madrid está muy complicado el trabajo, porque aquí los alquileres son los más altos (miembro de Baitul Muqarram, 04/09/2019).

Los hombres trabajan por cuenta ajena en comercios (fruterías, tiendas de alimentación y de artículos electrónicos) y en negocios de restauración anunciados como "indios" o "hindúes"- y también en actividades de economía sumergida como la de los "lateros" (Salguero, 2018, p. 127). La mayoría de las mujeres trabajan en sus casas al cuidado de sus familias. Unas y otros presentan en común otras dificultades como un escaso conocimiento de la lengua española, si bien tampoco parece obstáculo para la adecuada atención a la clientela de muchos de estos negocios. Se trata, por tanto, de un colectivo precarizado, similar al caso londinense (Eade y Garbin, 2002, 
p. 139) y muy especialmente al de otras ciudades como Roma (Priori, 2010 y 2017; Della Puppa, 2014) y Lisboa (Mapril, 2012, 2016 y 2018), conformando así un modelo de mercado laboral en el sur de Europa en el que los migrantes desempeñan ocupaciones similares generalmente vinculadas a la precariedad y, en ocasiones, a la exclusión social (King, Lazaridis y Tsardanidis, 2000).

Tampoco son un grupo cultural homogéneo. Sus integrantes proceden de distintas provincias, como Sylhet, Faridpur, Narayanganj, Barisal o Chittagong, y como en el caso italiano en el que existe una competencia dentro de la comunidad basada en el origen regional (Morad y Della Puppa, 2018), ello se traduce sobre el tejido asociativo local en varias agrupaciones informales de carácter regional, pues las "distintas etnias y dialectos o giros dialécticos dentro del bengalí, que suponen rasgos muy característicos" son "uno de los factores que sirven para diferenciar a la población y saber su lugar de procedencia", según fuentes municipales (Camacho, 2013, pp. 5-6).

En lo relativo a la adscripción política, las principales fuerzas políticas del país cuentan con representación en el barrio: la Awami League, de centroizquierda y actualmente en el gobierno; el conservador Bangladesh Nationalist Party (BNP), en la oposición y cuyo presidente en España es también presidente de la mezquita Baitul Muqarram; y el Jatiya Party, como alternativa a estos dos grandes partidos (Camacho, 2013, pp. 11-15). Todos y todas ellas, así como el resto de compatriotas residentes en España, están representados por la Asociación de Bangladés en España con sede también en Lavapiés. Esta asociación dice no tener filiación política alguna, "aunque existe una lucha constante por obtener la presidencia de esta entidad, por la relevancia social que tiene dentro de la comunidad y el prestigio social que esto trae consigo" (Camacho, 2013, p. 9).

Con un carácter más reivindicativo se creó la asociación Valiente Bangla en defensa de los derechos de los migrantes y que actualmente la conforman una decena de activistas. El protagonismo en el distrito del colectivo nacional y la carismática figura de su presidente, Mohammad Fazle Elahi, contribuyeron a conseguir el alquiler social de un local municipal en el número 14 de la calle Provisiones, muy próximo a la mezquita, y que inaugurarían en noviembre de 2017 el concejal García-Castaño y la responsable de Servicios Sociales del distrito Centro, Carmen Cepeda:

Es un alquiler social al Ayuntamiento. Pero nosotros también como la mayoría trabajamos con... pues no podemos pagar, porque como nosotros no tenemos dinero (...) Cinco o seis personas estamos trabajando cada día; porque uno se ha mudado de Madrid, otro también se ha ido de Madrid a otro sitio (...) Y también discutimos siempre con la embajada de Bangladés, que no hacen nada (miembro de Valiente Bangla, 04/09/2019).

Pese a su carácter marcadamente secular, sus miembros son también fieles activos de la Comunidad Musulmana Baitul Muqarram; además de colaborar puntualmente 
con esta en la organización de algunas actividades (Salguero, 2018, p. 125), "hasta el punto de que las fronteras entre ellos son menos rígidas de lo que su discurso sugiere", tal y como afirman Eade y Garbin para el caso londinense al hilo de los debates entre bangladesíes secularistas e religiosos (2006, p. 91). La doble militancia, religiosa y social, de algunos y algunas bangladesíes, sugiere adherirse al cuestionamiento de la tendencia de asociar "a las personas musulmanas con una lucha estructurada casi únicamente alrededor de la reclamación de derechos identitarios basados en la musulmaneidad", cuando la realidad es que su "conciencia de subalternidad no solo se estructura alrededor de una identidad religiosa no aceptada, sino también, y sobre todo, alrededor de una precariedad económica y laboral muy pertinaz en el caso de las poblaciones musulmanas" (Mijares y Lems, 2018, p. 126).

Para velar por los intereses de la clase empresarial bangladesí existe la Bussines Association Banglades, una patronal que "representa a todos los comerciantes que tienen algún negocio en nuestro país, aunque mayoritariamente están representados los que tienen un comercio en la zona" (Camacho, 2013, p. 9). La sede de esta organización, en el número 26 de la transitada calle Lavapiés, también alberga a la Asociación de Mujeres Progresistas de Banglades (o Banglades Progotishil Mohila Songstha), integrada por algunas de las esposas de los directivos de aquella y centrada en la atención e integración de las mujeres bangladesíes, muchas de ellas con un desconocimiento pleno del castellano, desempleadas y con escasa formación.

\section{HÍPER-DIVERSIDAD ISLÁMICA}

Si bien el cristianismo evangélico supera ligeramente al islam en número de lugares de culto en Lavapiés, el volumen de fieles que aglutina el islam es mayor: el salat del medio día de los viernes puede reunir en la mezquita Al Huda a más de un centenar de personas y en el Centro Religioso de Pakistaníes y en Baitul Muqarram en torno al medio millar en cada una, cifras que superan incluso a la gran Iglesia Filadelfia del Centro de la calle Rodrigo de Guevara, uno de los cultos pentecostales más importantes de la ciudad integrado en su mayoría por fieles de etnia gitana.

Una representatividad que da cuenta de una "islamización del espacio urbano" del barrio, como en otros casos del sur de Europa (Blanes y Mapril, 2013) o del sureste de Reino Unido (Baker, 2017). En este sentido, en septiembre de 2019 constaban inscritas en el Registro de Entidades Religiosas un total de ocho entidades religiosas musulmanas en el barrio de Lavapiés, junto a un lugar de culto adscrito a una de estas. De estas ocho entidades, sólo seis comunidades estaban en activo: la Comunidad Islámica Mezquita Al-Huda de Madrid, el Centro Religioso de Pakistaníes de España, la Comunidad Musulmana de Madrid Baitul Muqarram, la Comunidad Musulmana Senegalesa de Lavapiés "Mezquita de Al Taqua", la Comunidad Islámica Camino de la Paz (Madrid) y la Hazrat Sahjalal Lotifia Cultural Center (Bangladesh), la única no constituida como entidad religiosa ante el Ministerio de Justicia. El resultado es un 
total de seis lugares de culto islámico que pueden clasificarse por el criterio nacional, arrojando como primer resultado una creciente preeminencia del islam asiático que en los últimos años ha tomado el relevo al marroquí, concretamente tres mezquitas bangladesíes, una pakistaní, otra marroquí -la más veterana-, y otra senegalesa.

Las relaciones entre las comunidades musulmanas y entre estas y el resto de confesiones varía en función de qué comunidad se trate; al igual que las relaciones con los poderes públicos y el variado tejido asociativo del barrio. Comunidades como Al-Huda, integrada mayoritariamente por fieles de origen marroquí, o la bangladesí de Baitul Muqarram, muestran un claro interés por la inclusión en la vida pública del barrio:

Tenemos relación con el párroco católico de ahí, que se llama Santos. También el colegio concertado católico, Alfonso, al final de la calle Mesón de Paredes, donde hemos celebrado alguna vez el fin de Ramadán (imam de Al-Huda, 25/10/2016).

Si abrimos las puertas la gente conoce a los musulmanes y saben cómo somos, tenemos que compartir las cosas también. Si en Bangladés voy a una casa, me invitan a algo, y eso también hay que hacerlo en España, ser más abiertos (miembro de Baitul Muqarram, 4/4/2017).

En el caso del islam bangladesí, la mezquita más antigua que este colectivo tiene en el barrio es la citada Baitul Muqarram. Esta comunidad se gestó en la década pasada entre migrantes bangladesíes musulmanes residentes en Lavapiés, en el seno de otras experiencias asociativas, como la Asociación de Bangladés en España, del mismo modo que su homónima de Lisboa a través de la Luso-Bangladeshi Association (Mapril, 2014, p. 6). Se constituyó primero como asociación cultural en 2003 con el nombre de "Centro Cultural Islámico Internacional España Madrid", abriendo la primera mezquita en la calle Peña de Francia, el Centro Cultural Islámico de Bangladesh en Madrid. En 2009 se constituyó como entidad religiosa ante el Ministerio de Justicia con el nombre de "Comunidad Musulmana de Madrid Baitul Muqarram" (en bengalí "la casa sagrada"), en referencia a la mezquita nacional, situada en Daca. La conocida como "mezquita de Bangladés" abre sus puertas desde 2008, siendo hasta el momento la más grande de las existentes en el barrio y que acoge a un mayor número de fieles, hasta 500 en el salat de los viernes, no sólo bangladesíes, pues a la misma también acuden, aunque en menor proporción, creyentes de otras nacionalidades residentes mayormente en el barrio y alrededores (Salguero, 2018: 126). Baitul Muqarram fue concebida como una "comunidad religiosa inmigrada", cuyo mismo nombre evoca a la mezquita más importante del país asiático, situada en la capital del país, Daca (Salguero, 2019, pp. 67-68).

Desde los últimos años, la comunidad ha intensificado su visibilización en el espacio público, en el marco de un progresivo reconocimiento al colectivo bangladesí por parte de las instituciones municipales, y muy especialmente durante el período 
del Gobierno local de Ahora Madrid (2015-2019) (Salguero, 2018, pp. 135). En este orden, ha promovido la creación de redes relacionales basadas en la pertenencia confesional y étnica, y la inclusión de la identidad cultural propia en el contexto de la acogida a través de dos estrategias: el contacto con las instituciones y con otros actores de la sociedad civil; y la proyección en la esfera pública de una serie de repertorios seculares para el cambio social, frecuentemente relacionados con la comunidad inmigrada de creyentes (Salguero, 2019, p. 75).

Yo vivo aquí desde 2004 y tengo relaciones con todas las comunidades, con la comunidad africana, marroquí, pakistaní, bangla... Estamos intentando luchar desde la calle Provisiones número 7: hay que dejar la mezquita abierta al vecindario (miembro de Baitul Muqarram, 04/07/2019).

La segunda mezquita bangla, de tamaño bastante más pequeña que la anterior, se encuentra en un local bajo de la calle Calatrava. Hazrat Sahjalal Lotifia Cultural Center (Bangladesh), cuyo nombre conmemora al sufí Hazrat Shah Jalal que difundiría el islam en el territorio de Bengala en la primera mitad del siglo XIV, cuenta con bastante menos representatividad que Baitul Muqarram, lo que contribuye a que tenga una presencia casi invisible en la esfera pública. Las relaciones entre ambas comunidades son escasas. Esta comunidad forma parte de la Bangladesh Anjumane-Al-Islah Spain, una organización no constituida formalmente en España y que responde a un movimiento internacional presente en aquellos lugares del mundo donde existen asentamientos bangladesíes significativos, como el barrio del Raval en Barcelona, donde se encuentra el Centro Cultural Islámico Lotifia Fultoli Barcelona Spain (Martín-Saiz, 2019, p. 122; Salguero, 2018, p. 126; 2019, pp. 68). Ambas comunidades se adscriben a la tradición Barelvi, seguidor de la escuela jurisprudencial suní Hanafi y con gran implantación en el sur de Asia.

La última mezquita bangla fue inaugurada en la primavera de 2019 en otro local bajo de la calle Oso. Con la llegada de la Comunidad Islámica Camino de la Paz (Madrid) se puso fin a un espacio de culto que desde 1997 había sido el referente para los musulmanes marroquíes, la Comunidad Islámica Mezquita Al-Huda de Madrid (Salguero, 2018, p. 126; 2019, pp. 65), coincidiendo con la gran etapa de asentamiento de esta población en el distrito Centro de Madrid, y especialmente en el barrio de Lavapiés. Al-Huda continua en Lavapiés, ahora en la calle Magdalena, más visible y transitada. Este cambio no se corresponde con ningún enfrentamiento entre ambos colectivos nacionales, de hecho, el anterior equipo de gobierno ha colaborado en la transición de una comunidad a otra, como demuestra el propio asiento registral, en el que consta constan como representantes legales dos bangladesíes, y como email de contacto de la comunidad el del anterior imam marroquí, Mohamed Ajana, entonces secretario también de la Comisión Islámica de España, que es el órgano que representa a las comunidades musulmanas de España ante los poderes públicos. 
Camino de la Paz es una comunidad integrada por unas 70 personas, todos hombres, agrupados en Islamic Forum Madrid, una filial de la organización transnacional Islamic Forum Europe (IFE), fundada en 1988 en Reino Unido por migrantes musulmanes de Bangladés y que, con el tiempo, fue implantando nuevas filiales en otras ciudades europeas. Islamic Forum está relacionada con la organización política islamista-de Bangladés, Jamaat-e-Islami, con origen en el movimiento revivalista Deobandi gestado en India y Pakistán. Jamaat-e-Islami propone una organización política y una práctica del islam más escrituristas $\mathrm{y}$, por tanto, opuestas a proyectos nacionalistas y seculares de otras fuerzas como la conservadora BNP. Como sus vecinos Barlevi, también cuentan con grupos afines en Barcelona, como la mezquita Darul Amaal, abierta en 2018 en la calle Vistalegre (Martín-Saiz, 2019, p. 22). Es la primera vez que Islamic Forum tiene en Madrid una mezquita propia, pues antes sus integrantes rezaban en Baitul Muqarram. Durante este tiempo las relaciones del grupo con el resto de la comunidad trascurrieron sin incidencias, según se extrae de las entrevistas, contando con una primera sede en un local arrendado frente a Baitul Muqarram, y en donde se organizaban actividades de formación y difusión en torno al islam y la cultura bangladesí (Camacho, 2013, p. 33).

Las diferencias existentes en el territorio de Bangladés entre el movimiento Barelvi y otros como el Deobandi (tabligh), encarnado en Europa en el Islamic Forum, no parecen manifestarse en el caso de la ciudad de Madrid. Caso distinto es el de Barcelona, en donde la mezquita bangla más antigua, la Shah Jalal Jame en el Raval, de inspiración Barelvi, sufrió la escisión de un grupo de tradición Deobandi, que abrió en 2018 su propia mezquita, la Darul Amaal, en los bajos de un edificio residencial en la calle Vistalegre (Martín-Saiz, 2019, p. 22). Baitul Muqarram, por su parte, no tiene un posicionamiento expreso en este debate: "en la mezquita somos todos iguales", explican. Sin embargo, este carácter aperturista e integrador que se manifiesta, por ejemplo, en haber servido de lugar de culto durante muchos años para los devotos barelvi y deobandi, enmarca a Baitul Muqarram en una corriente secular, la cual, dependiendo de quién ostente la presidencia, oscila entre posiciones más conservadoras, o más de "izquierda" y liberales.

En este contexto de híper-diversidad nacional, étnica y religiosa, la Junta de Distrito municipal ha llevado a cabo acciones como incluir a Lavapiés en el circuito de escenarios de Las noches de Ramadán, un evento cultural promovido por el Ayuntamiento en colaboración con Casa Árabe, y que en 2016 reuniría por vez primera una partida específica de 150.000 euros de los presupuestos municipales para festejar el Ramadán (Salguero 2018, pp. 127-126). Otra acción significativa tuvo lugar la tarde del 30 de mayo de 2017 con la presentación pública en la plaza del barrio por el delegado de Salud, Seguridad y Emergencias del Ayuntamiento, Javier Barbero, del acuerdo del Pleno municipal de la proposición de Ahora Madrid de reconocer al distrito centro "libre de islamofobia" y que dotaba a la Unidad de 
Gestión de la Diversidad de la Policía Local de competencias para recoger denuncias ciudadanas especialmente relacionadas con la islamofobia.

Con Manuela Carmena, de Ahora Madrid, hay más acercamiento. (...) el anterior concejal no decía ni hola, y ahora el concejal cuando necesito algo me dice, "vale, posiblemente". Ahora hay más acercamiento (miembro de Baitul Muqarram, 04/04/2017).

Es decir, el espacio público de Lavapiés, por el momento, ha sido un espacio tolerante, apoyado en el reconocimiento social de un vecindario progresista, e institucional del Ayuntamiento de Ahora Madrid, que contrasta con otras realidades como las oposiciones vecinales a la apertura de mezquitas (fenómenos NIMBY) en lugares tan dispares como el barrio del Albaicín en Granada (Rosón, 2008), como Premià de Mar y Singuerlín en Santa Coloma de Gramanet (Moreras, 2008) o Los Bermejales en Sevilla (Tarrés y Salguero, 2010). Un espacio que desde junio de 2019 está sujeto a la gestión municipal del nuevo gobierno local del conservador Partido Popular y su alcalde, Martínez Almeida, con el apoyo de otros dos partidos, Ciudadanos (liberal) y Vox (extrema derecha).

Nunca hemos tenido para el rezo del cordero tantos problemas. Ni el anterior gobierno del Partido Popular dio tantos problemas, pero este año ha habido cambios y hasta el viernes antes no nos dieron la respuesta (miembro de Baitul Muqarram, 04/09/2019).

\section{BAITUL MUQARRAM EN EL ESPACIO PÚBLICO}

A partir de lo expuesto puede comprenderse la significativa y creciente presencia del colectivo musulmán bangladesí en la esfera pública local. Una presencialidad que ha venido aumentando con el tiempo, parejo a la consolidación del colectivo migrante, el cual abarca un amplio tejido humano e institucional, integrado por un importante número de personas procedentes de Bangladés y descendientes de estas que forman parte del paisaje cotidiano de Lavapiés; y por una red de asociaciones en distintos ámbitos sociales, políticos y económicos, algunas de las cuales cuentan con cierta visibilidad entre los movimientos sociales de la ciudad y/ o participan en la vida pública local a través de diversos programas y proyectos sociales y culturales promovidos por entidades públicas y privadas.

Al igual que en el caso italiano, esta visibilización es una apuesta de las organizaciones de migrantes bangladesíes por el reconocimiento de la diferencia, manteniendo "formas transnacionales de pertenencia" a través de la organización de festivales, de la conmemoración de días nacionales y de la celebración de rituales religiosos (Mohad y Della Puppa, 2018). En Madrid, Baitul Muqarram ha puesto en marcha en los últimos años una estrategia de visibilización en el espacio público de repertorios tanto religiosos, como culturales y étnicos, casos de la celebración 
de los dos rezos anuales del Eid al-Fitr y el Eid al-Adha en las canchas deportivas municipales al aire libre del Casino de la Reina, que albergan a unos seis millares de personas y las convierten en una improvisada musala (Salguero, 2018, pp. 132-133).

Como es un barrio donde vive mucha gente musulmana, más de 7.000 o 10.000 personas, el Ayuntamiento deja una cosa fija para la oración, porque son dos fiestas muy importantes al año (...) La gente en la calle mira qué estamos haciendo. Yo como estoy organizando, lo veo. La gente mira porque en televisión no dicen qué es el Ramadán, la fiesta del cordero. ¿Por qué en las noticias en España eso sale muy poco cuando es un país donde viven bastantes musulmanes? (miembro de Baitul Muqarram, 04/04/2017).

Otros rituales religiosos son celebrados en un espacio que podría denominarse como "temporalmente público", caso del iftar anual de Ramadán al que son invitados representantes y gestores municipales y el vecindario en general, cita que también es aprovechada para plantear algunas necesidades y demandas:

Por vez primera han entrado dos concejales a la mezquita, han cenado con nosotros. He preguntado al presidente de la mezquita por qué no invitamos a nuestra oración al concejal para que sepa cuanta gente está ahí para hacer la oración (...) también al secretario del Ayuntamiento, a la jefa de los servicios sociales para que conozcan la comunidad musulmana, al concejal del distrito... (...) Le hemos pedido altavoces, y nos dijeron que para el próximo año nos los dejarían, porque para cada Eid gastamos 750 euros para los equipos (miembro de Baitul Muqarram, 04/04/2017).

El reconocimiento de la diferencia está manifiestamente presente en ambas citas, en las que se potencian elementos etno-religiosos en la búsqueda del reconocimiento social de sus particularidades. Son sus creencias y prácticas religiosas, y también sus costumbres las que se muestran públicamente, de manera que hasta el propio menú del iftar aporta información cultural sobre el grupo étnico y nacional. El énfasis inclusivo, por su parte, está presente, por ejemplo, al desmontar durante el ambiente relajado del encuentro y la comida el interesado binomio islam-violencia, lo que significa la alineación entre la comunidad y la sociedad, en términos de modernidad y transparencia; transparencia no sólo semántica, también performativa en los rezos colectivos al aire libre, a la vista de todos: "Estamos rezando, no tenemos nada que ocultar".

Nuestro propósito es que la gente sepa qué es el islam, porque el Corán no dice nada de matar a la gente, ni de terrorismo. Jesús habla de compartir el pan, y nuestro profeta también habla de compartir (...) La gente debe saber qué dice el Corán, qué dice nuestro profeta Muhammad; aunque no sea religiosa, no importa. Quiero que seamos abiertos, que seamos amigos y amigas, que haya integración, ese es mi sueño para Lavapiés (miembro de Baitul Muqarram, 04/04/2017). 
La visibilización en el espacio público también es acometida mediante la organización de actos seculares, casos del citado reconocimiento público del distrito Centro "libre de islamofobia" (30/05/2017), de una concentración contra los atentados de Barcelona y Cambrils (22/09/2017) o de la conmemoración de los sucesos de la Universidad de Daca en 1952 por la defensa de la lengua bengalí en los que murieron dos estudiantes a manos de la policía (21/02/2019). Estas tres apariciones en el espacio público se realizaron en la plaza de Lavapiés, un punto neurálgico de la vida comunitaria (Salguero, 2018, p. 122). Los tres fueron actos más minoritarios que las grandes puestas en escena del Eid, lo que no ha impedido que al menos uno alcanzara más resonancia pública que este, al estar vinculados otros actores como el Ayuntamiento. Si bien existen en el barrio otras comunidades en activo, fue Baitul Muqarram la que participaría activamente en el acto, celebrando después en su mezquita un iftar ante una nutrida representación municipal, señal de una fluida interlocución pública.

\section{CONGLUSIONES}

El caso del islam bangladesí en Lavapiés presenta significativas similitudes con los de otras ciudades europeas, muy especialmente con las del sur, como Roma y Lisboa. Estas semejanzas se manifiestan tanto en el colectivo migrante, como en las comunidades religiosas. Se trata de un colectivo migrante determinado por una generalizada precariedad y organizado en un heterogéneo tejido asociativo y político con concepciones diferentes del hecho migratorio. Las comunidades islámicas, por su parte, responden una variedad de diversas tradiciones devocionales, con distintas formas de organizarse en torno a unas creencias comunes; y también de relacionarse entre ellas mismas y con las instituciones y la sociedad en su conjunto.

Baitul Muqarram explica las estrategias de institucionalización de las comunidades musulmanas más consolidadas, no tanto por su trayectoria si las comparamos con la de las primeras comunidades marroquíes inmigradas de los años noventa, sino por su significativo volumen de fieles en Lavapiés, y su cada vez más intensa visibilización y participación en la vida pública del barrio y de la ciudad, en la cual también ha intervenido decisivamente el progresivo reconocimiento de este colectivo por parte del Ayuntamiento de Ahora Madrid (Salguero, 2018: 135; 2019: 75). Sin embargo, el nuevo ciclo político puede generar algunos cambios en el éxito de las relaciones entre el cabildo y la comunidad.

El vecindario bangladesí forma parte esencial de la multiculturalidad definitoria del barrio, recuperada también por la imagen de marca Lavapiés, que intenta atraer turistas e inversiones mostrando una multiculturalidad edulcorada con altas dosis de exotismo, en medio de un escenario de ocio sin fin. En este contexto aparentemente amable, pero plagado también de obstáculos como las dificultades crecientes en el acceso a la vivienda, la comunidad religiosa ha desempeñado un relevante papel en 
la vida social del vecindario bangladesí, promoviendo redes relacionales basadas en la pertenencia confesional y étnica, y la inclusión de la identidad cultural propia en el contexto de la acogida a través del contacto con las instituciones y con otros actores de la sociedad civil. En el seno de la comunidad de fieles también se han gestado una serie de repertorios seculares para el cambio social, frecuentemente relacionados con la comunidad inmigrada de creyentes.

El acceso y la visibilización en el espacio público en condiciones de igualdad con otros actores, confesionales y civiles, es comprendido por Baitul Muqarram como un derecho colectivo de ciudadanía, el derecho a la ciudad, propio de una sociedad plural. Es, por tanto, el espacio público, en tanto espacio para la alteridad, donde se expresa e identifica socialmente la diversidad religiosa (Salguero, 2018, p. 135), y que habrá de materializarse en una real y efectiva participación comunitaria junto a las instituciones y/o las asociaciones y ONG en asuntos locales de la vida social y política.

El pleno ejercicio de este derecho requiere en ocasiones para el colectivo inmigrado más condiciones que la titularidad misma. Para sortear estas dificultades añadidas, despliegan estrategias de visibilización en distintos espacios públicos (la plaza del barrio o las canchas deportivas) y "temporalmente públicos" cuando la mezquita se abre al vecindario. En estas citas la comunidad religiosa se alinea con la vida y política locales, adhiriéndose a repertorios de modernidad, por un lado, mediante la organización de eventos seculares públicos, en los que también se ponen en valor particularismos religiosos, étnicos y nacionales; y, por otro, a través de reiteradas muestras desestigmatizantes de transparencia ante el vecindario, la ciudadanía y las instituciones locales con motivo de la sospecha que sigue despertando el islam entre ciertos sectores de la sociedad española.

\section{BIBLIOGRAFÍA}

Alguacil, Julio (2008). Espacio público y espacio político: La ciudad como el lugar para las estrategias de participación. Revista Polis, vol. 7, n. 20, pp. 199-223. DOI: http://dx.doi.org/10.4067/S0718-65682008000100011

Alonso, Marta et al. (2010). Rituals islàmics en diáspora: Les comunitats musulmanes a Catalunya. Revista d'etnologia de Catalunya, n. 36, pp. 171-176.

Astor, Avi y Griera, Mar (2016). La gestión de la diversidad religiosa en la España contemporánea. En: Arango, Joaquín et al. (dirs.). Anuario CIDOB de la Inmigración 2016. Barcelona: CIDOB, pp. 248-270.

Baker, Julius (2017). 'Is it a mosque?' The Islamization of space explored through residents' everyday 'discursive assemblages'. Global Studies in Culture and Power, vol. 26, n. 1, pp. 12-32. DOI: https://doi.org/10.1080/1070289X.2017.1321861

Berger, Peter (1967). The Sacred Canopy: Elements of a Sociological Theory of Religion. Garden City, NY: Doubleday. 
$\underline{\text { El islam en el espacio público de los barrios multiculturales...-O. Salguero Montaño }}$

Blanes, Ruy y Mapril, José (eds.) (2013). Sites and Politics of Religious Diversity in Southern Europe. Leiden: Brill.

Borja, Jordi y Muxí, Zaida (2003). El espacio público: ciudad y ciudadanía. Barcelona: Electa.

Briones, Rafael (2002). Significado y funciones de las religiones en el tercer milenio. En: Luna, Manuel (ed.). La ciudad en el tercer milenio. Murcia: UCAM, pp. 289-310.

Camacho, José (2013). Resumen de las reuniones con los grupos de población bangladesí de Lavapiés. Madrid: Centro Social Comunitario Casino de la Reina del Ayuntamiento de Madrid.

Caravaca, Rubén (2008). La España multicultural. Lavapiés, un mundo aparte. Cambio 16, n. 1894, pp. 24-25.

Carrión, Fernando (2007). Espacio público: punto de partida para la alteridad. En: Segovia, Olga (ed.). Espacios públicos y construcción social. Hacia un ejercicio de ciudadanía. Santiago de Chile: Ediciones Sur, pp. 79-97.

Casanova, José (2007). La inmigración y el nuevo pluralismo religioso: una comparación Unión Europea/ Estados Unidos. Revista CIDOB d'Afers Internacionals, n. 77, pp. 13-39.

Castilla-Vázquez, Carmen (2007). Mujeres en transición: la inmigración femenina africana en España. Migraciones internacionales, n. 33, pp. 143-171. DOI: https:// doi.org/10.17428/rmi.v9i33.290

Davie, Grace (2004). New Approaches in the Sociology of Religion: A Western Perspective. Social Compass, vol. 55, n. 1, pp. 73-84. DOI: https://doi. org/10.1177/0037768604040791

Della Puppa, Francesco (2014). Uomini in movimento. Il lavoro della Maschilità fra Bangladesh e Italia. Torino: Rosenberg \& Sellier.

Dench, Geoff, Gavron, Kate y Young, Michael (2006). The New East End: Kinship, Race and Conflict. Londres: Perfile Book.

Eade, John (1996). Nationalism, Community, and the Islamization of Space in London. En: Metcalf, Barbara, D. (ed.). Making Muslim Space in North America and Europe. Berkeley: University of California Press, pp. 217-233.

Eade, John y Garbin, David (2002). Changing Narratives of Violence, Struggle and Resistance Bangladeshis and the Competition for Resources in the Global City. Oxford Development Studies, vol. 30, n. 2, pp. 137-149. DOI: https://doi. org/10.1080/13600810220138258

Eade, John y Garbin, David (2006). Competing visions of identity and space: Bangladeshi Muslims in Britain. Contemporary South Asia, vol. 15, n. 2, pp. 81-193. DOI: https://doi.org/10.1080/09584930600955291

Eguren, Joaquín y Fernández, M.M. (2011). Árabes y musulmanes en el Madrid del siglo XXI. En: Gil-Flores, Daniel (ed.). De Maŷrit a Madrid. Madrid y los árabes, del siglo IX al siglo XXI. Madrid: Casa Árabe, pp. 234-243. 
García-García, Sergio (2014). \#Policíasenacción. El Plan de Seguridad de Lavapiés, Contested_Cities. Working paper series [en línea], n. 14006. Disponible en: http:// contested-cities.net/working-papers/2014/policiasenaccion-el-plan-de-seguridadde-lavapies/

Gómez, Mayte (2012). El barrio de Lavapiés, laboratorio de interculturalidad. Dissidences. Hispanic Journal of Theory and Criticism, vol. 1, n. 2(12), pp. 1-42.

Hamid, Sadek (2011). British Muslim Young People: Facts, Features and Religious Trends, Religion. State and Society, vol. 39, n. 2-3, pp. 247-261.

Hudson, Wayne (2003). Religious Citizenship. Australian Journal of Politics and History, vol. 49, n. 3, pp. 425-429. DOI: https://doi.org/10.1111/1467-8497.00296

King, Russell, Lazaridis, Gabriella y Tsardanidis, Charalambos (eds.) (2000). Eldorado or Fortress? Migration in Southern Europe. Londres: Palgrave Macmillan.

Lefebvre, Henri (1968). Le Droit à la ville. París: Anthropos.

Luckmann, Thomas (1967). The invisible religion: The problem of religion in modern society. Nueva York (NY): Macmillan.

Mapril, José (2012). Islão e Transnacionalismo: Uma Etnografia entre Portugal e o Bangladesh. Lisboa: ICS-Imprensa de Ciências Sociais.

Mapril, José (2014). A Shahid Minar in Lisbon: Long Distance Nationalism, Politics of Memory and Community among Luso-Bangladeshis. South Asia Multidisciplinary Academic Journal [en línea], 9. Disponible en: http://journals.openedition.org/ samaj/3733

Mapril, José (2016). A past that hurts: memory, politics and transnationalism between Bangladesh and Portugal. En Palmberger. Monika y Tošić, Jelena (eds.). Memories on the Move: Experiencing Mobility, Rethinking the Past. Londres: Palgrave, pp. 247-270.

Mapril, José (2018). Person, Death and Gender between Lisbon and Dhaka. En: Havick, Philip, Mapril y Saraiva, Clara (eds.). Death on the Move: managing narratives, silences and constraints in a trans-national perspective. Newcastle: Cambridge Scholars Press, pp. 98-117.

Martín-Sáiz, Guillermo (2019). El islam del Raval: sus oratorios y organizaciones. Revista Internacional de Organizaciones, n. 22, pp. 109-128. DOI: https://doi. org/10.17345/rio22.109-128

Méndez, Juan R. (2019). Políticas de lo colectivo en entornos de migración transnacional: Posibilidades de lo bangladesí en Lavapiés (Madrid). Disparidades. Revista de Antropología [en línea], vol. 74, n. 2, e021. Disponible en: http://dra.revistas.csic. es/index.php/dra/article/view/617. DOI: https://doi.org/10.3989/dra.2019.02.021

Mesoneros, Ramón (2005). El antiguo Madrid: paseos históricos-anecdóticos por las calles y casas de esta villa (1st. ed. 1968). Alicante: Biblioteca Virtual Miguel de Cervantes. 
Mijares, Laura y Lems, Johanna M. (2018). Luchando contra la subalternidad: las reivindicaciones de la población musulmana en Madrid. Revista de Estudios Internacionales Mediterráneos, 24, pp. 109-128. DOI: https://doi.org/10.15366/ reim2018.24.007

Morad, Mohammad y Della Puppa, Francesco (2018). Bangladeshi migrant associations in Italy: transnational engagement, community formation and regional unity. Ethnic and Racial Studies, vol. 42, n. 10), pp. 1788-1807. DOI: https://doi.org/10.1080/0 1419870.2018 .1515441

Moreno, Isidoro (1998). ¿Proceso de secularización o pluralidad de sacralidades en el mundo contemporáneo? En: Nesti, Arnaldo (coord.). Potenza e impotenza della memoria. Scritti in onore de Vittorio Dini. Roma: Tibergraph Editrici, pp. 170-184.

Moreras, Jordi (2008). "Hoy han hablado en la tele, de la mezquita del barrio". Los medios de comunicación en el contexto de los conflictos en torno a los oratorios musulmanes en Cataluña. En: Martínez Lirola, María (ed.). Inmigración, discursos y medios de comunicación. Alicante: Instituto Alicantino de Cultura Juan GilAlbert, pp. 127-142.

Moreras, Jordi (2017). ¿Qué islam para qué Europa? Hacia una antropología del islam posmigratorio en Europa. Revista CIDOB d'Afers Internacionals, n. 115, pp. 1337.

Peñalta, Rocío (2010). Dos espacios multiculturales de Madrid: Lavapiés y la Puerta del Sol. Ángulo Recto: Revista de estudios sobre la ciudad como espacio plural, vol. 2, n. 2, pp. 111-117.

Pérez, Vicente (2009). Intervención y rehabilitación, 1998-2008. Madrid: Ayuntamiento de Madrid y Federación Regional de Asociaciones de Vecinos.

Priori, Andrea (2010). Vita segreta delle 'etnie': politica e stratificazione sociale a Banglatown. Zapruder. Rivista di storia della conflittualità sociale, n. 22, pp. 3954.

Priori, Andrea (2017). Bangladeshi multi-scalar im/mobilities: Between social aspirations and legal obstacles. New Diversities, vol. 19, n. 3, pp. 29-42.

Ramírez, Ángeles y Mijares, Laura (2018). Rethinking Re-islamization: On Muslims and Gender in Spain. En: Planet, Ana I. (coord.). Observing Islam in Spain: Contemporary Politics and Social Dynamics. Leiden: Brill, pp. 140-157.

Repo, Nora (2013). Multiplicity of Women's Religious Expression: Albanian Muslim Women in the Former Yugoslav Republic of Macedonia. En: Blanes, Ruy y Mapril, José (eds.). Sites and Politics of Religious Diversity in Southern Europe. Leiden: Brill, pp. 177-205.

Rodríguez-Brochado, Adrián (2017). Resignificando la ciudad. Espacio público desde/ para la ciudadanía en Esta es una Plaza de Lavapiés. Revista San Gregorio, n. 17, pp. 118-125. 
Rodríguez-Medela, Juan, Salguero, Óscar y Sánchez-Cota, Ariana (2016). Cartografía de la ciudad capitalista. Transformación urbana y conflicto social en el Estado Español. Madrid: Traficantes de Sueños.

Rosón, Javier (2008). ¿El retorno de Tarik? Comunidades etnorreligiosas en el Albayzín granadino. Granada: Universidad de Granada.

Salguero, Óscar (2018). Baitul Muqarram: el islam en el espacio público del barrio de Lavapiés. Revista de Estudios Internacionales Mediterráneos, n. 25, pp. 111-138. DOI: https://doi.org/10.15366/reim2018.25.007

Salguero, Óscar (2019). Estrategias de institucionalización del islam en contextos migratorios: el caso de Baitul Muqarram. Revista Internacional de Organizaciones, n. 22, pp. 55-79. DOI: https://doi.org/10.17345/rio22.55-79

Salguero, Óscar y Hejazi, Hutan (2020). El islam en el espacio público madrileño. Disparidades. Revista de Antropología [en línea], vol. 75, n. 1, e011. Disponible en: http://dra.revistas.csic.es/index.php/dra/article/view/753. DOI: https://doi. org/10.3989/dra.2020.011

Sequera, Jorge (2014). Gentrificación en el Centro Histórico de Madrid: el caso de Lavapiés. En: Janoschka, Michael y Hidalgo, Rodrigo (eds.). La Ciudad Neoliberal. Gentrificación y exclusión en Santiago de Chile, Buenos Aires, Ciudad de México y Madrid. Santiago de Chile: Instituto de Geografía, Pontificia Universidad Católica de Chile / Departamento de Ciencia Política y Relaciones Internacionales y Universidad Autónoma de Madrid, pp. 233-255.

Shepard, William E. (2004). The diversity of Islamic thought: towards a typology. En: Taji-Farouki, Suha y Nafi, Bachir (eds.). Islamic Thought in the Twentieth Century. Londres: Tauris, pp. 61-103.

Tarrés, Sol y Salguero, Óscar (2010). Musulmanes en Andalucía. En: Briones, Rafael (dir.). ¿Y tú (de) quién eres? Minorías religiosas en Andalucía. Barcelona: Icaria, pp. 289-377.

Téllez, Virtudes y Madonia, Salvatore (2019). Visibilizing 'Invisibilized' Spanish Muslim Youth. En: Planet, Ana I. (coord.). Observing Islam in Spain: Contemporary Politics and Social Dynamics. Leiden: Brill, pp. 113-139.

Thiebaut, Carlos (1998). Vindicación del ciudadano. Barcelona: Paidós. 
